\title{
TECNOLOGIA E EDUCAÇÃO: A FERRAMENTA QUIZ COMO COMPLEMENTO NO ENSINO DE QUÍMICA
}

\author{
(*) SOUSA, R. L. (IFRN); LOPES, B. G. (IFRN); LOPES, S. R.G. (IFRN); LEOPOLDINO,K. S.M. \\ (IFRN).
}

\section{RESUMO}

Nos dias atuais a tecnologia está cada vez mais presente no processo de consolidação do conhecimento, visto que tem chegado até mesmo em lugares de difícil acesso, tornando assim, um meio de interagir com pessoas em outros continentes, estando conectado em tudo que está acontecendo no momento, no país e no mundo, tornando-se uma ferramenta tecnológica como um veículo de suma importância na área educacional. Diante disso, o objetivo deste trabalho é relacionar o ensino de química através da ferramenta lúdica Quiz como complemento no ensino, visando favorecer no processo ensino aprendizagem e na construção de conhecimentos, com a finalidade de motivar através da tecnologia, inovação e participação dos alunos nas aulas de química. A metodologia desse trabalho se deu através de um questionário com perguntas objetivas com a participação de 17 professores de química, atuantes de rede de ensino municipal, estadual e federal, para que através dos dados obtidos evidenciar a relação do uso da tecnologia, como recurso de ferramenta tecnológica didático. Os resultados foram satisfatórios, visto que os professores está cada vez mais aprimorando os conhecimentos tecnológicos com o intuito de motivar os alunos a associar a tecnologia como ferramenta cognitiva no ensino de química tornando seu conhecimento significativo para a aprendizagem.

PALAVRAS-CHAVE: tecnologia, quiz, ensino de química.

\section{TECHNOLOGY AND EDUCATION: THE TOOL QUIZ AS SUPPLEMENT IN CHEMICAL TEACHING}

\section{ABSTRACT}

Nowa days technology is increasingly present in the process of consolidation of knowledge, as it has come even in hard to reach places, making it a means of interact with people on other continents, and is connected to everything that is happening at the moment in the country and the world, making it a technological tool as a short vehicle importance in education. Thus, the objective of this work is to relate the teaching chemistry through fun tool Quiz to supplement teaching, aiming to encourage the learning process and development of knowledge, in order to motivate through technology, innovation and participation of students in chemistry classes. The methodology of this work was through a questionnaire with objective questions with the participation of 17 teachers chemistry acting of municipal education, state and federal network, so that through the data show the relation between the use of technology as a teaching tool technology feature.

The results were satisfactory, as the teachers are increasingly improving the technological knowledge in order to motivate students to associate the technology as a cognitive tool in chemistry teaching making your significant knowledge for learning.

KEY-WORDS: technology, quiz, chemistry teaching. 


\section{TECNOLOGIA E EDUCAÇÃO: A FERRAMENTA QUIZ COMO COMPLEMENTO NO ENSINO DE QUÍMICA}

\section{INTRODUÇÃO}

Nos dias atuais a tecnologia está cada vez mais presente no processo de consolidação do conhecimento, visto que a mesma tem chegado até em lugares de difícil acesso, tornando assim, um meio de interagir com pessoas em outros continentes, estando conectado em tudo que está acontecendo no momento, no país e no mundo. Diante disso, o uso das tecnologias com essa rede de conhecimentos só vem favorecer uma troca de informações contribuindo para um aprendizado mais interativo. Desta forma, o professor torna-se um elemento imprescindível, por ser um mediador de conhecimentos na construção dos alunos. De acordo com Filatro (2005, p.27) "Estatísticas oficiais de informação e comunicação estão de fato cada vez mais presentes nos ambientes escolares e universitários".

Com isso, essa tecnologia tem sido essencial na área educacional fazendo com que o aluno busque mais conhecimento utilizando novos métodos tecnológicos. (AUSUBEL 2006, p.15) ele acredita que [...] "a aprendizagem significativa ocorre quando a nova informação "ancora-se" em conceitos relevantes (subsunçores) preexistentes na estrutura cognitiva". Logo, [...] "passou a ser entendido como um processo mais amplo. (FILATRO, 2005, p.33). Em que essa aprendizagem,[...]“Envolve-além de planejar, preparar, projetar, produzir e publicar texto, imagens, gráficos sons e movimentos, simulações, atividades e tarefas relacionados a uma área de estudo" (FILATRO, 2005, p.33).

Portanto, o objetivo deste trabalho é relacionar o ensino da química através da ferramenta lúdica Quiz como complemento no ensino, visando favorecer no processo ensino aprendizagem na construção de conhecimentos, com a finalidade de motivar através da tecnologia, inovação e participação dos alunos nas aulas de química. Com isso, [...] um objetivo importante da química é que os alunos possam utilizar seus conhecimentos na solução de problemas e, de fato, isso representa um dos recursos didáticos mais utilizados na sala de aula (POZO; 2009 p.177).

Por conseguinte, o ensino de química visa motivar os alunos a associar a tecnologia como uma ferramenta cognitiva tornando seu conhecimento significativo para a aprendizagem. De acordo com as Orientações Curriculares para o ensino médio (OCNEM) aborda que:

A discussão de aspectos sócios científicos articuladamente aos conteúdos químicos e aos contextos é fundamental, pois propicia que os alunos compreendam o mundo social em que estão inseridos e desenvolvam a capacidade de tomada de decisão com maior responsabilidade, na qualidade de cidadãos, sobre questões relativas à Química e à Tecnologia, e desenvolvam também atitudes e valores comprometidos com a cidadania planetária em busca da preservação ambiental e da diminuição das desigualdades econômicas, sociais, culturais e étnicas. (BRASIL, 2006, p. 119). 
Dessa maneira, a ferramenta tecnológica Quiz, é um jogo de perguntas e respostas lúdica podendo ser utilizando no ensino de química que favorece no processo ensino aprendizagem visando um ensino de forma mais dinâmica e interativa desenvolvendo a capacidade cognitiva do aluno, para complementação no ensino estimulando o aluno a buscar mais e mais conhecimento.

\section{MATERIAIS E MÉTODOS}

A metodologia desse trabalho se deu através de um questionário com perguntas objetivas com a participação de 17 professores de química do sexo masculino e feminino, cuja faixa etária está compreendida entre 24 e 52 anos, a partir de um senso realizado com respostas dos próprios professores atuantes de rede de ensino municipal, estadual e federal, em que os dados obtidos venham evidenciar a relação do uso da tecnologia, como recurso no planejamento escolar e se mesmos utilizam a ferramenta tecnológica didático Quiz em suas aulas,como complemento inovador de ensino de química para melhoramento na formação do aluno e contribuição na formação acadêmica.

\section{RESULTADOS E DISCUSSÕES}

Através do questionário pode-se comprovar através do Gráfico 01, que $53 \%$ (nove) disseram que sim, ou seja, os professores utilizam a ferramenta Quiz como recurso didático em suas aulas e $47 \%$ (oito) dos professores disseram que não. Percebemos os dados e podemos observar a importante dessa ferramenta tecnológica na formação educacional acadêmico e profissional,e podemos constatar que ainda tem muitos profissionais na área que não utilizam dessa ferramenta, sabendo que a própria tecnologia está cada vez exigindo do profisional a busca de aperfeiçoamento na área profissional e para ser um bom profissional é preciso está sempre atualizado nas novas tecnologias,sabendo que aqueles alunos devem sai dali para uma vida profissional na sociedade, e o professor deve capacita-se para pode passa todas aquelas informações necessária na aprendizagem do aluno.

Gráfico 1- Referente ao professor para saber se ele (a) utiliza a ferramenta Quiz, como recurso didático em suas aulas de química.

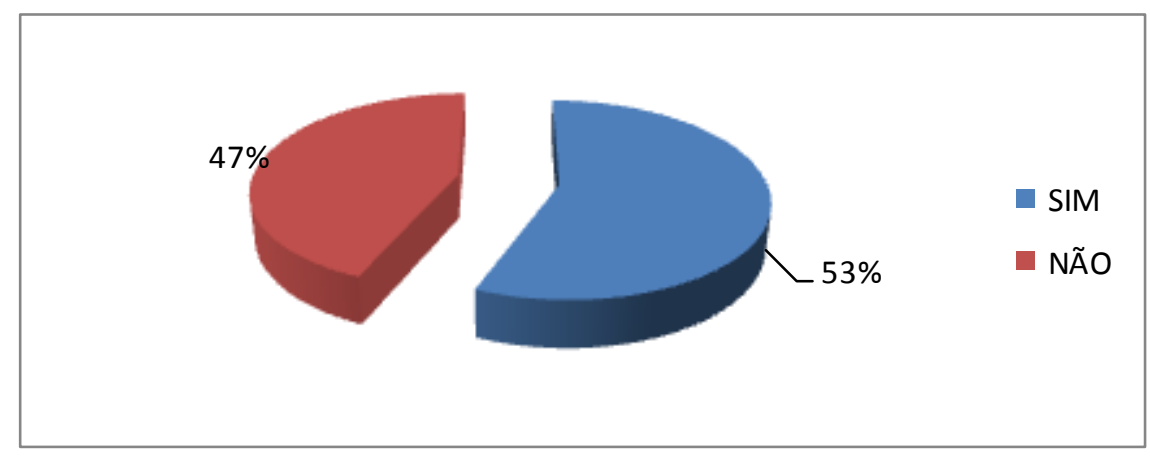

Fonte: SOUSA, R. L. 2016.

4a Semana de Química - IFRN, 2016 
No Gráfico 02. Refere-se a aplicação da ferramenta lúdica Quiz se foram satisfatórios e se esse recurso a aprendizagem torna mais significativa, e $82 \%$ (quatorze) dos professores responderam que Sim. Através desse resultado podemos perceber que essa ferramenta demonstram rendimentos satisfatório na aprendizagem do aluno. Podemos constatar que $18 \%$ (três)dos professores responderam que não utiliza essa a ferramenta.

Gráfico 2- Referente à aplicação da ferramenta Quiz, se os resultados são satisfatórios e se as mesma torna aprendizagem mais significativa.

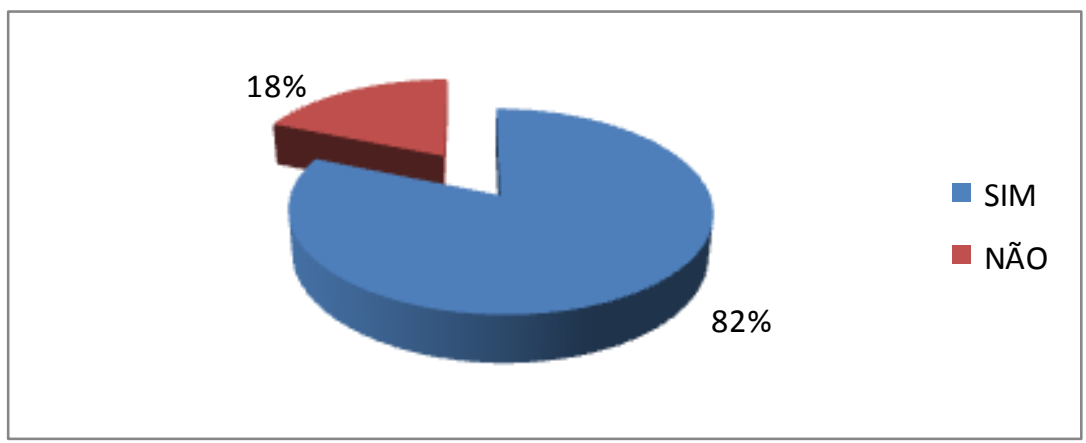

Fonte: SOUSA, R. L. 2016.

Como argumenta Freire (1993, p.9), "O homem aprende a realidade por meio de uma rede de colaboração na qual cada ser ajuda o outro a desenvolver-se, ao mesmo tempo em que também se desenvolve. Todos aprendem juntos e em colaboração". Para o aluno tenha uma aprendizagem mais significativa não depende somente do professor e materiais didáticos, mais depende também do aluno querer aprender, por isso é importante que o professor inove as aulas usando as tecnologias como ferramenta no aprendizado do aluno.

No Gráfico 03. Refere se o quiz como ferramenta inovadora estimula o aluno positivamente a buscar mais conhecimentos através dos erros, e $82 \%$ (quartoze) dos professores responderam que sim, e 18 \% (três) responderam que não.

Gráfico 3- Refere se o Quiz como ferramenta inovadora estimula o aluno positivamente a buscar mais conhecimentos através dos erros.

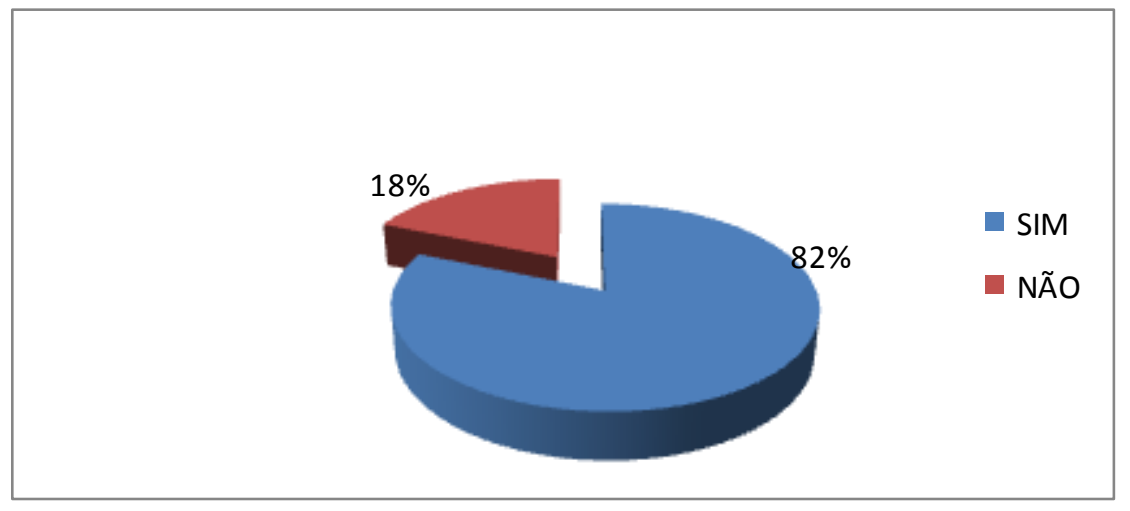

Fonte: SOUSA, R. L. 2016.

4a Semana de Química - IFRN, 2016 
Os resultados mostram a importância da inovação nas aulas como, por exemplo, a aplicação da ferramenta lúdica Quiz, estimula os alunos participarem das aulas de maneira mais prazeroso, aprendendo de forma interativa, que com isso, ocorre uma a absorção mais rápida dos conteúdos em a aprendizagem dos alunos através dos erros e a tentativa de acertos, fazem com que os alunos busquem mais conhecimentos, aprendendo assim de forma positivamente além de fazer com que a aula seja interativa e dinâmica.

\section{CONCLUSÃO}

Mediante estudos, constatou-se os resultados satisfatórios, visto que a maioria dos professores está cada vez mais aprimorando os conhecimentos pedagógicos e tecnológicos com o intuito de motivar os alunos e associar a tecnologia como ferramenta cognitiva no ensino de química tornando assim a aprendizagem mais significativa por meios de estratégias instrucionais.

\section{AGRADECIMENTOS}

Os autores agradecem ao Instituto Federal de Educação, Ciência e Tecnologia do Rio Grande do Norte - IFRN, Campus Ipanguaçu pela disponibilização do espaço cedido e ao Conselho Nacional de Desenvolvimento Científico e Tecnológico (CNPq) pelas bolsas concedidas e apoio financeiro para realização do projeto.

\section{REFERÊNCIAS}

AUSUBEL, D. P. A aprendizagem significativa: a teoria de David Ausubel. São Paulo: Moraes, 1982.

BRASIL. Ministério da Educação (MEC). Secretaria de Educação Básica (SEB). Orientações curriculares para o ensino médio: ciências da natureza, matemática e suas tecnologias. Vol. 2. Brasília, DF: MEC/SEB, 2006.

FREIRE, Paulo. Política e educação. São Paulo: Cortez, 1993.

FILATRO, Andrea. Design Instrucional Contextualizado: educação e tecnologia. Ed. Senac. São Paulo - SP, 2003.

POZO, Juan Ignacio; CRESPO. Miguel Ángel Gómez. A aprendizagem e o ensino de ciências: do conhecimento cotidiano ao conhecimento científico. 5.Ed.- Porto Alegre: Artimed, 2009. 